\title{
Universal health coverage in Iran: Where we stand and how we can move forward
}

\author{
Haniye Sadat Sajadi ${ }^{1}$, Elham Ehsani-Chimeh ${ }^{1}$, Reza Majdzadeh*2
}

Received: 25 Aug 2018

Published: 22 Feb 2019

\begin{abstract}
Over the last 4 decades, many initiatives have been implemented to accomplish equitable accessible health care for all Iranian citizens. The latest reform to address universal health coverage (UHC) is Health Transformation Plan (HTP), which resulted in significant improvements in health outcomes. Nevertheless, several challenges in the fields of sustainability of resources, service delivery, and health governance continued to exist. These challenges should be addressed in next steps to achieve the defined goals. To tackle these challenges, a number of practical solutions can be proposed, including making health financing more resilient, defining and implementing cost control policies and cost-effective package of services, changing the current method of providers' payment, and ensuring good governance in the health system.
\end{abstract}

Keywords: Heath Care Reform, National Health Programs, Health Policy, Iran

Conflicts of Interest: None declared

Funding: None

*This work has been published under CC BY-NC-SA 1.0 license.

Copyright $\odot$ Iran University of Medical Sciences

Cite this article as: Sajadi HS, Ehsani-Chimeh E, Majdzadeh R. Universal health coverage in Iran: Where we stand and how we can move forward. Med J Islam Repub Iran. 2019 (22 Feb);33:9. https://doi.org/10.47176/mjiri.33.9

\section{Introduction}

Universal health coverage (UHC) offers all people- irrespective of their living standards- to receive the health services they need, including prevention, promotion, treatment, rehabilitation, and palliation with sufficient quality and ensures that using health services does not cause financial hardship (1). The dimensions of UHC include the full spectrum of the necessary services, financial support to meet health expenses and the extent of population coverage (2). Since UHC was suggested, different countries around the world have implemented various policies to provide universal health care $(3,4)$.

Corresponding author: Dr Reza Majdzadeh, rezamajd@tums.ac.ir

1. National Institute for Health Research, Tehran University of Medical Sciences, Tehran, Iran

2. Knowledge Utilization Research Center, Community Based Participatory Research Center and School of Public Health, Tehran University of Medical Sciences, Tehran, Iran
Islamic Republic of Iran has made several revisions in the health system in the past 4 decades to materialize health for all. When UHC strategy was considered as a priority for all health systems, Iran embedded components of UHC in its national development plans (NDPs) (5). Achieving UHC was more emphasized by general health policies, announced by the Supreme Leader in 2014 (6). The country has witnessed measures towards UHC in the recent years $(7,8)$. Nevertheless, there are still some challenges that should be addressed.

What are these challenges and which interventions are

\section{$\uparrow$ What is "already known" in this topic:}

In Iran, many revisions have been done to provide health services for all, and the latest plan was Health Transformation Plan with a variety of lessons learned.

\section{$\rightarrow$ What this article adds:}

There are 3 important challenges in achieving the goals of Universal health coverage: sustainability of resources, wellestablished and updated service delivery arrangement, and strong governance arrangement. To tackle with these challenges, we need a number of complex interventions that are defined based on a system thinking approach. Additionally, we need a strong national commitment to establish and institutionalize changes to implement required interventions. 
suitable to solve them?

To answer these questions, this manuscript introduces the latest and the most fundamental plan of the country to achieve UHC. Then, it summarizes the main challenges faced by Iran to achieve UHC. Finally, it proposes some practical and critical interventions to solve the current problems.

\section{Health transformation plan: An initiative to achieve UHC}

Implementing several transformation plans along with making other health-related changes in the country led to significant accomplishments in different areas, such as providing primary health care, improving health indexes, controlling epidemics, eradicating some diseases, disease prevention, diagnosing and treating diseases, extending health care insurance, producing health resources both qualitatively and quantitatively, improving the quality of health care and service, and developing pharmaceutical industry, etc. However, a situation analysis of Iran's health system shows that there were still deep-rooted problems and that the necessary interventions did not either take place or did not bring about the preferred results (Panel 1).

These problems intensified during 2012-2013, due to US sanctions. The intensity of these problems disrupted the normal functioning of a large part of the health system and led to serious crisis. Critical condition of the health system on the one hand and the security considerations on the other necessitated an urgent response to address them and to make some changes. However, mere recognition of the urgency of the issue did not suffice and further incentives and motivation were required. In 2013, following the elections in Iran, 2 remarkable events took place. Health became the top priority of the new government and an unwavering determination and commitment was developed to solve the health system's problems engendered in political leaders. The second event was a boost in the financial resources of the health sector. Fortunately, the low share of the health expenditure of the gross domestic product (GDP) increased due to the following measures:

- An annual lump sum paid to Ministry of Health and Medical Education (MoHME) to contain or preclude crisis arising from the shortage of medicine and to compensate budget deficits (2013)
- MoHME's annual budget increased by 37.8\% (2014)

- Iranian Health Insurance Organization (IHIO)' budget increased by $66 \%$ (2014)

- The premium increased from $5 \%$ of the total income to $6 \%$

- Also, the $1 \%$ of value-added-tax (VAT) and $10 \%$ of saving originated from public subsidy program were allocated to MoHME (2014).

Thus, devising a new transformation plan through providing the required resources to make the necessary changes in the health system, meeting the objectives to protect people financially against health expenses, institutionalizing the equity in the access to the benefits of health services, improving the quality of services, and more coverage became feasible.

Health transformation plan (HTP), the most extensive transformation plan to provide access to UHC, was developed in 2013 and became effective in 2014. HTP had 5 key goals:

1. Provide sustainable financial resources in the health sector

2. Financial protection against health expenses

3 . Increase access to high-quality health care and facilities

4. Improve health service delivery

5. Make improvements beyond the health sector

Numerous interventions were made to meet these goals, and most important of which are presented in Table 1.

\section{The main challenges in achieving universal health} coverage

The authors have summarized the main 3 challenges of the country's health system in achieving UHC: sustainable provision of financial resources, delivery of efficient and equitable services, and good governance $(11,12)$.

Despite the allocation of a relatively appropriate share of GDP to health following HTP (13), unsustainability in the provision of public resources remains a big challenge. This unsustainability, which is seen in both the amount of funds allocated and the timely allocation of funds to the health sector, has led to the inability of the health insurance organizations in timely reimbursement of costs of the health service and delivering units, including hospitals, pharmacies, and companies providing medical equipment and substances. The reimbursement of health costs by

Panel 1. The main challenges of Iran' health system before health transformation plan (HTP)*

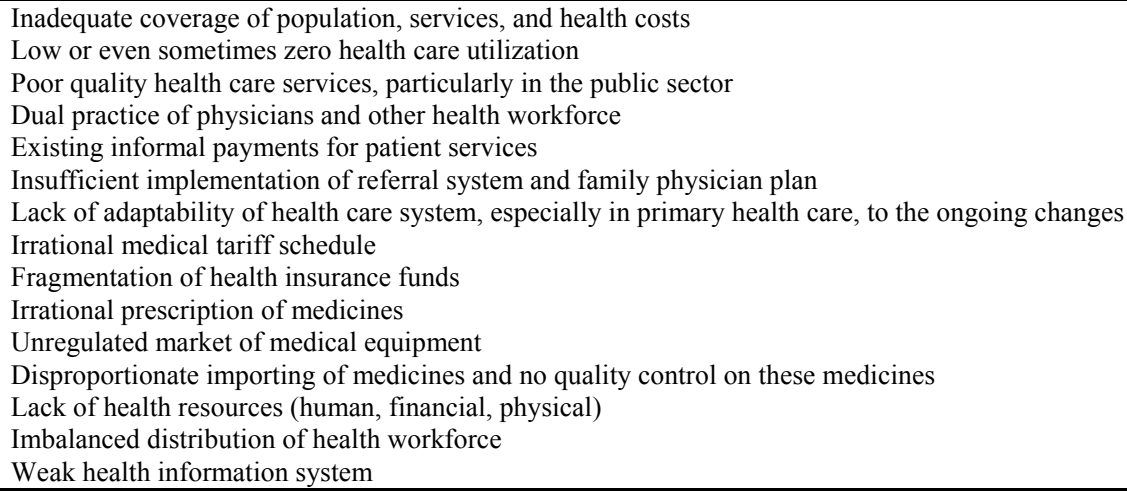


Table 1. The goals and interventions implemented since 2013 to achieve universal health coverage

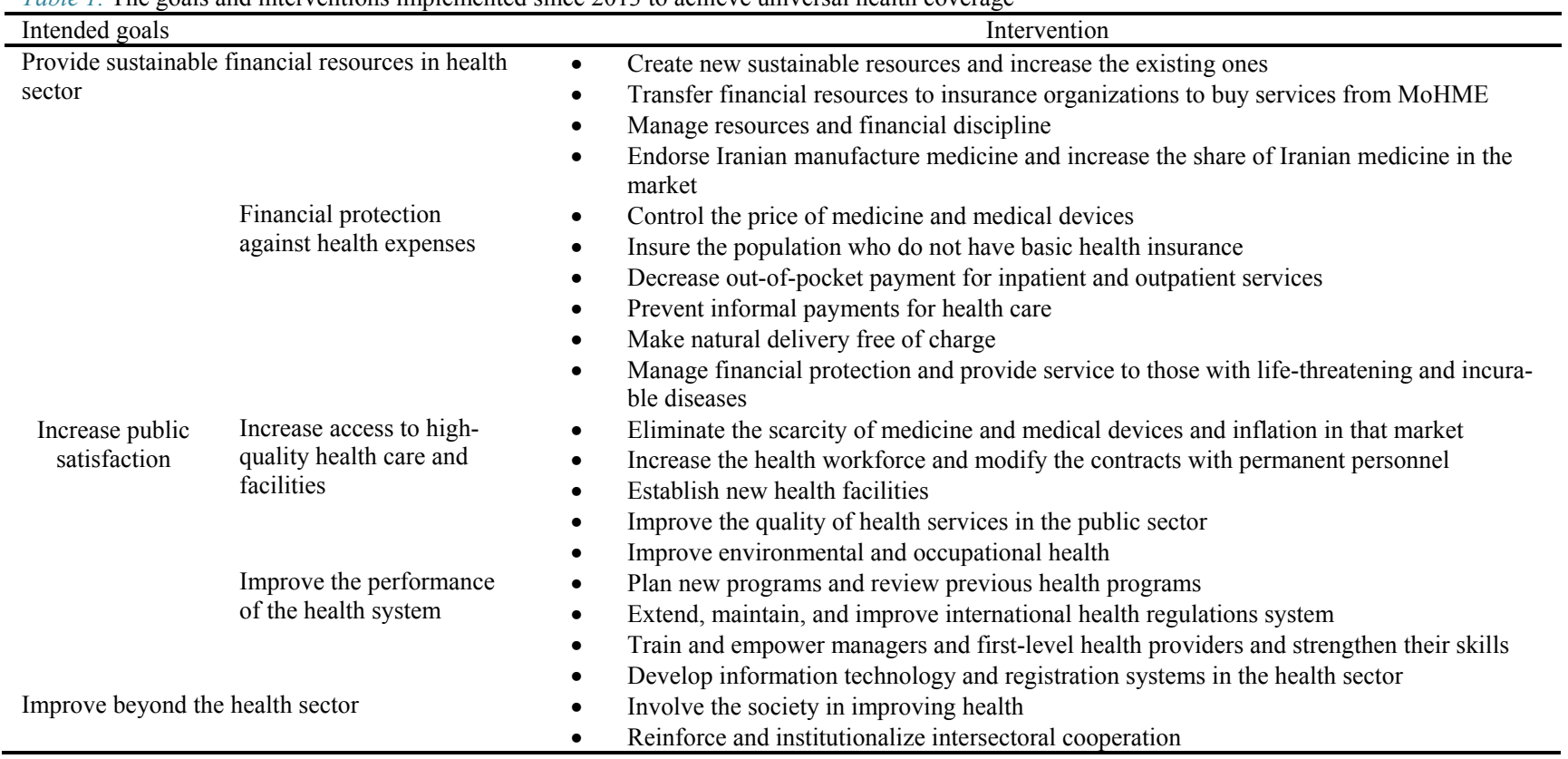

health insurance organizations has led to lengthy delays in compensating for the services delivered by health workforce (14). These delays are a serious threat to the increase of informal patient payments asked by the providers in the public sector (15), followed by increases in out-of-pocket payments. The solution put forth by the government for these delays (selling bonds) is not a sustained financing method, as this method is itself a way of expenditure beforehand for future resources -though with higher interest rates. In other words, this method does not solve the delay in paying demands and spends from future resources. Apart from this unsustainability, Iran will be witnessing a growth in its population and, more importantly, the phenomenon of aging in near future. The occurrence of noncommunicable diseases (NCDs), the need to provide care for chronic diseases, and the entry of novel technologies all raise health costs in the long run. Another issue is the continuous fluctuation of exchange rates that exist due to the country's political issues. Furthermore, the dependency on oil and fluctuations in its revenues and the international sanctions imposed by the US (16) have negatively affected the financial resources of the health system. The second challenge is the extensiveness of the services covered by public resources and the inefficient platform for service delivery. The services covered by public resources are wide-ranging and have gradually entered into health packages without following a specific prioritized rationale. Some of the services of this package are not costeffective and their insurance coverage does not seem to be economic under the current circumstances of the health financial resources. In other words, the limited allocation of resources to some of these services lack allocative efficiency and health resources are used in places where they should not be (15). Moreover, despite the increase in the share of health from GDP, the goals of financial risk protection, including the incidence of catastrophic and im- poverished expenditures, have not improved sufficiently (17).

The inappropriateness of premiums set for the current services without performing actuary analyses and method of payment based on fee for service (FFS) to health workforce have raised the risk of informal patient payments and induced demands. Both situations can affect the share of out-of-pocket (OOP) payments; in fact, the share of OOP is still high. If this indicator is reduced to $20 \%$, then, catastrophic and impoverishment expenditures will be prevented. Thus, under the current circumstances, it is not possible to achieve the goals of financial risk protection of households due to health expenditures, which is one of the important goals of UHC (18). This can be seen in the high share of OOP from the total health expenditure compared to countries with similar conditions in term of the GDP. Despite the recommendation of a desirable service delivery model, such as family physician, for over a decade and recognition of the referral system, no proper platform for relevant health services has been introduced. The prerequisite for solving this problem is the actualization of the electronic health record and the defined communication channels between different levels of delivery. A few years have passed since the establishment of country-wide comprehensive health service centers and the urban family physician program pilots in Mazandaran, Fars, and East Azerbaijan provinces (in a different form). However, still, no definitive decision has been made about the model and combination of service delivery models in the country.

If we were to compare the types of diseases and their health risks in Iran with other countries, we would see that the main burden of diseases is related to NCDs and their risk factors. Thus, in designing health service delivery, priority should be given to reviewing and defining services in platforms appropriate for NCDs.

The third challenge is related to the health system gov- 
ernance, which is very complex in nature, as it is affected by the intertwined relations between different players in the health system. Heath policymaking is not evidenceinformed as much as expected, and instead of benefitting from evidence, most of them are affected by powers beyond the control of the health sector or by personal interests, such as pressure from the members of parliament or authorities of localities. When a policymaker asks for evidence, due to problems associated with the research governance and health information systems, evidence is not handed over to the decision-maker properly and at the right time (19). Hence, it results in making various policies and programs that have either not been developed based on scientific principles or that have been designed well but are not implemented with operational meticulousness. Due to involvement of different players in the decision-making and service delivery arena (insurance funds, various types of hospitals owned by banks, municipalities), the full responsibility to provide public health is not completely organized. Integrating health insurance organization is a legal obligation that has not been realized yet. Separating the management duties and service provision is another topic that has been brought up many times in the upstream documents, which has not reached a tangible result. Hence, there are certain ambiguities in the lines of command, execution, and responsiveness.

The activity of the private sector in the health market and how it is managed is another main issue of the current governance planning. The private sector is considered one of the main determinant players of the health market, as it holds more than $70 \%$ of health delivery in the outpatient sector and constitutes $17 \%$ of hospitals. The National Households' Expenditure and Income Survey also indicates that the most OOP are made in the outpatient and private sectors (20). In spite of this, an acceptable supervision is not performed on the activity of this sector and, basically, there is no specific control mechanism to control either the induced demand or the quality of the services.

Another chronic problem of the health system's governance is related to the conflict of interests of the professional groups and the profit expectations to make money from health services. The existing conflicts of interests are a strong hindrance toward implementing major health reforms. For example, the physicians' dual practice can be pointed out. In spite of many efforts made to eliminate this phenomenon in Iran and the lessons learnt in other countries and the positive impacts that they have witnessed (e.g., Turkey) and the golden opportunity given by allocation of the resources for the HTP in 2014, conflict of interests did not allow the elimination of this phenomenon. Thus, the negative effects of dual practice still overshadow the country's health system.

The public's level of awareness and expectations and their access to a plethora of data have increased. Thus, it is unlikely to implement key decisions in the health system without having a plan for engaging and informing the public. For example, the public demand for utilizing advanced technologies, which might not necessarily be effective, and service delivery with little cost-effectiveness can be highlighted. It is highly important to inform the public about the impacts of such technologies to alleviate public resistance and social crises.

\section{Future agenda for achieving UHC}

Bearing in mind the aforementioned challenges and considering that achieving $\mathrm{UHC}$ is an obligation for Iran and not an option, the following stages of achieving UHC can be summarized in the execution of tough interventions that cannot be achieved without serious efforts and wise measures:

1- Taking into account resilient economics in the health sector, cost control policies, and operationalizing them: Under the circumstances wherein the exchange rates fluctuate and there is instability in international diplomacy, strengthening the health sector- especially in the financing arrangement- seems inevitable. Although the country is accustomed to utilizing oil revenues, one intervention can change the policies of revenue collection from oil revenues to impose taxes on unhealthy products, services, and substances (eg, tobacco and soft drinks). Using this method, dependence on oil will be terminated and can be considered a big national extra sectoral intervention. Financing through value-added tax (more than the current level) is another example related to resilient economics that can be implemented in the health sector. Another example is increasing the premiums for the health insurance. Given the 2018 budget act and considering that the funds for insurance companies are going to be reduced, frugality is a compulsion and no longer an option.

2- Replacing the current health benefit package by a cost-effective package of services: Setting priorities to find those services that should be financed by public money is a difficult task. Thus, strong evidence for decisionmaking and widespread support is needed to make the right decision. The first aspect relies more on the technical dimensions. Many acceptable methods have been tried to provide good evidence for prioritization of services. Implication of the health technology assessment is an example of these approaches. However, the second aspect is related to the method of attracting support and engaging stakeholders in the implementation of the decision. Imagine the amount of resistance among people or expert groups if we were to exclude a service or drug from the list of insurance based on scientific evidence. If not correctly managed, this resistance could turn into a social crisis. To manage such situations, in addition to technical aspects, we should encourage stakeholder participation (creating awareness, attracting support, coalition) and make major changes and institutionalize them with social solidarity and strong leadership.

To avoid financial risks, when defining a package, we must identify at-risk and vulnerable groups. In other words, service delivery to deprived individuals should always receive special consideration, and prioritization of services should be based on burden of diseases and subpopulations affected by them.

3- Changing the method of provider's payment: For years, there has been debate on changing the method of provider's payment from open-ended FFS to close-ended 
diagnosis-related groups (DRG) as one of the major reforms of the country's health system. This intervention, however, cannot be easily implemented, especially because the health workforce has gotten used to this method over the years. Our practical recommendation for this change is to conduct preliminary studies (eg, trials) to compare the proposed methods of payment and utilize their results to bring about change across the country. For this important intervention, one must keep in mind that service providers have a very powerful social position. Some of them are either policymakers outside the health sector or government officials who can profoundly affect the country's high-rank policymakers. In addition to conflict of interests, the beliefs shaped by individuals make the process of changing the method of payment difficult, and thus there must be a national determination for change. Turkey's experience in omitting dual practice was an important lesson that showed that albeit this is not an easy task, it is doable.

The country has shifted towards FFS to benefit more from professional services (21). However, as long as the health workforce shortage exists and the necessary human resources are not equally spread across the entire country, changing the current method of payment is challenging. Additionally, there are technical debates on the stages of these changes, such as changes in the diagnostictherapeutic coding techniques of diseases or automation synced with these classifications; and it seems that it can be done if there is a will to do so. However, first, it should be done in the form of a pilot study and then changes should be made considering the results of the pilot study and the details.

4- Having good governance in health: There are 4 important steps to achieve good governance: separating stewardship duties and service delivery, managing conflict of interests, institutionalizing the evidence-informed decisionmaking, and increasing community participation in health decision-making. It would be an oversimplification to assume that separating duties means to change the organizational positions of health players; such separation is aimed to determine the positions and lines of authority, responsibility and accountability of the stakeholders. This procedural change may not seem very favorable at first, as it changes the sources of power but will benefit the health system in the long-term. Conflict of interests can be controlled to some extent by reconsidering the combinations of some of the main policy-making and decision-making councils. All we have to do is to choose those individuals for decision-making who do not benefit from the decisions. Nevertheless, the influence of professional groups who are close to the top-level administrators has always been an important challenge of reform in the health system. A part of this problem can be addressed by developing a roadmap for future actions and making it public. Thus, it is important to institutionalize evidence-informed decision-making in lieu of personal decision-making and to transform health issues to community demands by involving the community in decision-making. Both these topics require culture-building. Changing decision-making procedures cannot be done overnight. Community partici-

pation is also dependent on the rate of social and political development. In 2017, Iran witnessed its first National Health Assembly, which is now taking shape across the provinces (22). For the first time, such a program has been launched in the country at such an extensive level and we hope that it could be used to achieve the goals of UHC. One of the practical aspects of good governance is having a plan and documentations for evaluating progress. It appears that in spite of the presence of technical and capable units, we still lack an explicit program, which can be the basis for practice and evaluation.

\section{Conclusion}

Three important challenges exist in achieving the goals of UHC: sustainability of resources, well-established and updated service delivery arrangement, and strong governance arrangement. To tackle these challenges, we need a number of complex interventions to strengthen the health system. Such interventions should be defined based on a system thinking approach, in which we can better capture the wisdom of diverse stakeholders in designing solution to system problems. In addition, we need strong national commitment to establish and institutionalize changes and implement them. A successful example of association of evidence and commitment has been seen in extending Iran's primary health care. Therefore, there is hope that the country will be able to take steps toward sustainable reform of the health system and accomplish UHC using the required knowledge and skill and with a will to change.

\section{Acknowledgments}

None.

\section{Conflict of interest}

HSS and EE are academic members of Iran's National Institute for Health Research where RM was its head until May 2018.

\section{References}

1. World Health Organization. World Health Report, 2010: health systems financing the path to universal coverage. Geneva: 2010.

2. Boerma T, Eozenou P, Evans D, Evans T, Kieny MP, Wagstaff A. Monitoring progress towards universal health coverage at country and global levels. PLoS Med. 2014;11(9):e1001731.

3. Cotlear D, Nagpal S, Smith O, Tandon A, Cortez R. Going universal: how 24 developing countries are implementing universal health coverage from the bottom up: World Bank Publications; 2015.

4. Reich MR, Harris J, Ikegami N, Maeda A, Cashin C, Araujo EC, et al. Moving towards universal health coverage: lessons from 11 country studies. Lancet. 2016;387(10020):811-6.

5. Vosoogh Moghaddam A, Damari B, Alikhani S, Salarianzedeh M, Rostamigooran N, Delavari A, et al. Health in the 5th 5-years Development Plan of Iran: main challenges, general policies and strategies. Iran J Public Health. 2013;42(1)Supple1:42-9.

6. Meskarpour Amiri M, Mehrabi Tavana A. Successful implementation of General Health Policies in the Islamic Republic of Iran: barriers and mechanisms. Eastern Mediterranean Health Journal. IN PRESS http://www.emro.who.int/in-press/research/successful-implementati on-of-general-health-policies-in-the-islamic-republic-of-iran-barriersand-mechanisms.html [10 Oct 2018] 
7. Letafat M, Beyranvand T, Aryankhesal A, Behzadifar M, Behzadifar M. Universal Health Coverage (UHC) in Iran. Iran J Pub Health. 2018;47(7):1061-2.

8. Moradi-Lakeh M, Vosoogh-Moghaddam A. Health sector evolution plan in Iran; equity and sustainability concerns. Int J Health Policy Manag. 2015;4(10):637.

9. Lankarani KB, Alavian SM, Peymani P. Health in the Islamic Republic of Iran, challenges and progresses. Med J Islam Repub Iran. 2013 Feb;27(1):42-9.

10. Abolhallaje M, Ramezanian M, Abolhasani N, Salarian Zade H, Hamidi H, Bastani P. Iranian Health Financing System: Challenges and Opportunities. World Appl Sci J. 2013;22(5):662-666.

11. Sajadi HS, Majdzadeh R. Who would be the ideal minister to run the current health system of Iran? Int J Prev Med. 2017;8.

12. Iran joins UHC2030. Available from at https://www.uhc2030.org/ news-events/uhc2030-news/article/iran-joins-uhc2030-483050/

13. World Health Organization. Health systems financing: the path to universal coverage. 2010. Available from: http://www.who.int/ whr/2010/en/

14. Ibrahimipour H, Maleki MR, Brown R, Gohari M, Karimi I, Dehnavieh R. A qualitative study of the difficulties in reaching sustainable universal health insurance coverage in Iran. Health Policy Plan. 2011;26(6):485-95.

15. Davari M, Haycox A, Walley T. The Iranian health insurance system; past experiences, present challenges and future strategies. Iran J Pub Health. 2012;41(9):1.

16. Aloosh M. How economic sanctions compromise cancer care in Iran. Lancet Oncol. 2018;19(7):e334.

17. Moradi T, Naghdi S, Brown H, Ghiasvand H, Mobinizadeh M. Decomposing inequality in financial protection situation in Iran after implementing the health reform plan: What does the evidence show based on national survey of households' budget? Int J Health Plan Manag. 2018.

18. Mirabedini SA, Hashemi SMEF, Asiabar AS, Rezapour A, AzamiAghdash S, Amnab HH. Out-of-pocket and informal payments in Iran's health care system: A systematic review and meta-analysis. Med J Islam Repub Iran. 2017;31:70.

19. Majdzadeh R, Yazdizadeh B, Nedjat S, Gholami J, Ahghari S. Strengthening evidence-based decision-making: is it possible without improving health system stewardship? Health Policy Plan. 2011;27(6):499-504.

20. Statistical Center of Iran. National Houshold's Expenditure and Income Survey. 2014.

21. Ehsani-Chimeh E, Sajadi H S, Majdzadeh R. Iran towards universal health coverage: The role of human resources for health . Med J Islam Repub Iran. 2018;32 (1):578-582

22. Farshad AA, Rostamigooran N. The National Health Assembly, a way to increase community participation in health decision-making. Soc Determinant Health. 2016;2(2).51-52. 